\title{
Analysis, Voltage Control and Experiments on a Self Excited Induction Generator
}

\author{
Birendra Kumar Debta, Kanungo Barada Mohanty \\ Department of Electrical Engineering \\ National Institute of Technology, Rourkela-769008, India \\ e-mail: bkbiren@gmail.com,dr.kbmohanty@rediffmail.com
}

\begin{abstract}
In this paper dynamic analysis, closed loop voltage control and experiments on a self excited induction generator are presented. Electromagnetic torque, active power and reactive power are controlled under dynamic conditions of varied load, excitation capacitance and shaft speed, A closed loop voltage control scheme using a PWM Voltage Source Converter (VSC), dc link capacitor and a P-I voltage controller is proposed and implemented. This scheme generates constant voltage and variable frequency using the converter which also acts as a reactive power compensator. The frequency of stator voltage and current is varied by changing the error proportional gain making it attractive for wind energy conversion system. The simulation is done using MATLAB environment and the experimental results are also presented in this paper.
\end{abstract}

\section{Key words}

Self excited induction generator (SEIG), sinusoidal pulse width modulation (SPWM), reactive power compensation, voltage control, wind energy conversion system.

\section{Introduction}

Windy areas, waterfalls, reservoirs, high tide locations are extremely helpful for generating clean and economical electrical energy by proper harnessing mechanism. Throughout the globe in last three to four decades generation of electricity out of these renewable sources has created wide interest. Growing interest in water management and sustainable environment toward a sustainable world has awaken new sources of hydro energy. Among these are the run-of-river plants to produce electricity using induction generators. The induction generator self excitation phenomena is reviewed in [1]. The brushless construction, robustness, low maintenance requirements, absence of DC power supply for field excitation, small size, self protection against short circuits are the advantages of asynchronous generator over the synchronous and DC generators. The relatively poor voltage and frequency regulation and low power factor are its weaknesses [1]. The frequency and magnitude of voltage generated by the self excited induction generator (SEIG) is completely governed by the rotor speed, the excitation and the load [2]. There exist minimum and maximum capacitance for the self excitation to occur i.e., voltage build up at a particular speed. Also it requires a minimum cut in speed for successful voltage build up and it has a maximum speed limit considering mechanical safety for a fixed excitation capacitance [3-4]. The effect of dynamic mutual inductance on voltage build up process of SEIG is discussed in [5]. The application of power semiconductor devices, controlled converter circuits, and control algorithms has resulted in suitable regulating schemes for self excited variable speed squirrel cage generators. From the electricity company standpoint, accurate controls of voltage and frequency can limit the electrical and mechanical stresses in the power system and deliver good quality energy. Already many circuits are proposed to control the output voltage and/or frequency $[6,7,8]$. Dynamic performance of SEIG feeding different static loads is discussed in [9]. Constant voltage operation using optimization tools is discussed in [10]. The above papers did not mention the effect of speed, excitation capacitance, mutual inductance on dynamic power variations and frequency of power exchange and line voltage. This paper exploits the possible ways to generate electrical power by analyzing the machine at loaded and varied speed conditions to extract the information regarding dynamic active power, reactive power and torque variations. The viability of a constant voltage and variable frequency generation scheme is analyzed. Experimental results are presented. As wind speed is statistical in nature, this scheme could be extended to a variable speed, constant voltage and variable frequency wind energy conversion system.

\section{Dynamic Analysis of SEIG}

A three phase induction machine can operate as a SEIG if a suitable capacitor bank is connected across its terminals and rotor speed is sufficient to have a negative slip when driven by a prime mover. Capacitor banks provides the necessary magnetizing current to start the voltage build up process which is determined by feeding the machine as an induction motor without load and measuring the current as a function of the terminal voltage variation. A complete dynamic equation of SEIG involving an RL load in stationary reference 
frame is developed and represented in a state space matrix form is given in Equation 1.

$$
\begin{aligned}
& p\left[\begin{array}{c}
i_{d s} \\
i_{q s} \\
i_{d r} \\
i_{q r} \\
v_{L d} \\
v_{L q} \\
i_{L d} \\
i_{L q}
\end{array}\right]=K\left[\begin{array}{cccccccc}
R_{s} L_{r} & -\omega L_{m}^{2} & -R_{r} L_{m} & -\omega L_{m} L_{r} & L_{r} & 0 & 0 & 0 \\
\omega L_{m}^{2} & R_{s} L_{r} & \omega L_{m} L_{r} & -R_{r} L_{m} & 0 & L_{r} & 0 & 0 \\
-R_{s} L_{m} & \omega L_{m} L_{s} & R_{r} L_{s} & \omega L_{s} L_{r} & -L_{m} & 0 & 0 & 0 \\
-\omega L_{m} L_{s} & -R_{S} L_{m} & -\omega L_{s} L_{r} & R_{r} L_{s} & 0 & -L_{m} & 0 & 0 \\
1 / C K & 0 & 0 & 0 & 0 & 0 & -1 / C K & 0 \\
0 & 1 / C K & 0 & 0 & 0 & 0 & 0 & -1 / C K \\
0 & 0 & 0 & 0 & 1 / L K & 0 & -R / L K & 0 \\
0 & 0 & 0 & 0 & 0 & 1 / L K & 0 & -R / L K
\end{array}\right]\left[\begin{array}{c}
i_{d s} \\
i_{q s} \\
i_{d r} \\
i_{q r} \\
v_{L d} \\
v_{L q} \\
i_{L d} \\
i_{L q}
\end{array}\right] \\
& +\left[\begin{array}{cc}
-L_{r} & 0 \\
0 & -L_{r} \\
L_{m} & 0 \\
0 & L_{m} \\
0 & 0 \\
0 & 0 \\
0 & 0 \\
0 & 0
\end{array}\right]\left[\begin{array}{l}
v_{d s} \\
v_{q s}
\end{array}\right]
\end{aligned}
$$

Where $\mathrm{i}_{\mathrm{ds}}, \mathrm{i}_{\mathrm{dr}}, \mathrm{i}_{\mathrm{qs}}, \mathrm{i}_{\mathrm{qr}}$ are respectively the stator and rotor currents in direct and quadrature axis and $\mathrm{v}_{\mathrm{ds}}$ and $\mathrm{v}_{\mathrm{qs}}$ are the initial direct axis and quadrature axis applied voltage and

$$
K=1 /\left(L_{m}^{2}-L_{1} L_{2}\right)
$$

As the magnetizing characteristic is nonlinear in nature, the magnetizing current is found for each iteration in terms of stator and rotor currents as

$$
I_{m}=\left\{\left(i_{d s}+i_{d r}\right)^{2}+\left(i_{q s}+i_{q r}\right)^{2}\right\}^{1 / 2}
$$

The magnetizing inductance is calculated from the experimentally plotted magnetizing characteristic relation between $\mathrm{V}_{\mathrm{g}}$ and $\mathrm{I}_{\mathrm{m}}$, through curve fitting to find the constants in the nonlinear equation and is given by [11]:

$$
L_{m}=\left(-0.0016 \times \exp \left(0.0056 \times I_{m}^{2}\right)\right)+0.271
$$

The per phase active and reactive power is given by the relation:

$$
\begin{aligned}
& P=\frac{1}{2}\left(v_{d s} i_{d s}+v_{q s} i_{q s}\right) \\
& Q=\frac{1}{2}\left(v_{q s} i_{d s}-v_{d s} i_{q s}\right)
\end{aligned}
$$

Developed electromagnetic torque relation is given by:

$$
T_{e}=(3 P / 4) L_{m}\left(i_{q s} i_{d r}-i_{d s} i_{q r}\right)
$$

d-q stationary reference frame to abc phase transformation is given by the relation:

$$
\begin{gathered}
v_{a s}=v_{q s}^{s} \\
v_{b s}=-(1 / 2) * v_{q s}^{s}-(\sqrt{3} / 2) * v_{d s}^{s} \\
v_{c s}=-(1 / 2) * v_{q s}^{s}+(\sqrt{3} / 2) * v_{d s}^{s}
\end{gathered}
$$

\section{Experiments on Self-Excited Induction Generator}

Schematic diagram for SEIG is shown in Fig.1. Magnetization characteristic is experimentally plotted for the $10 \mathrm{hp}, 50 \mathrm{~Hz}$ induction machine whose details are given in Appendix A., by moving the shaft of the machine by a dc shunt motor. It is shown in Fig.2. Mutual inductance as a function of magnetizing current is also experimentally determined and shown in Fig.3. Operating point should be chosen in the negative slope zone known as stable operating region.

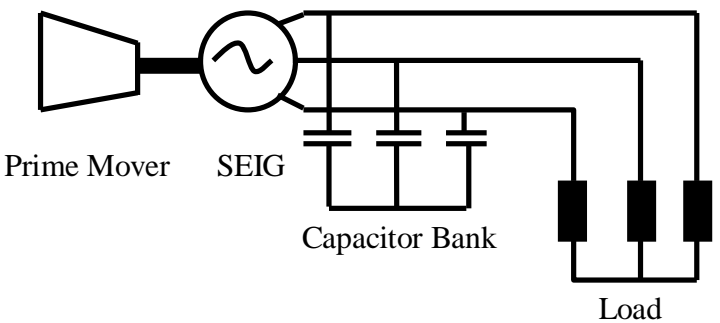

Fig. 1. Self excited induction generator system

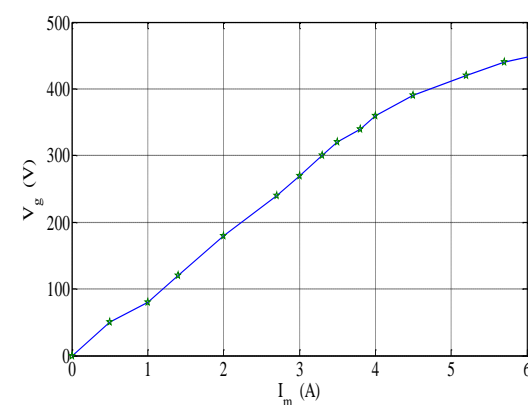

Fig.2. Magnetization characteristic of induction machine under consideration

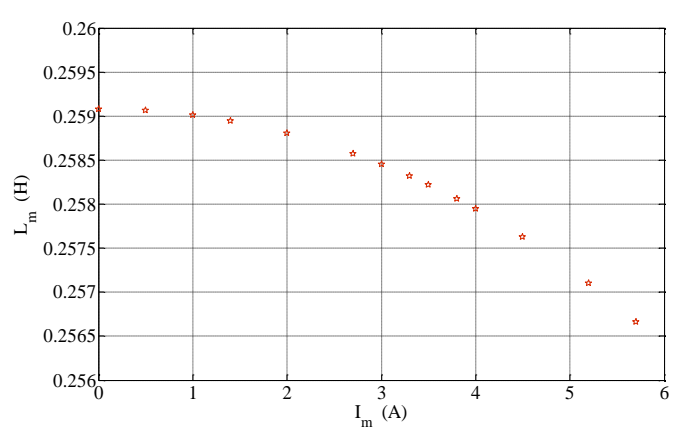

Fig.3. Variation of Mutual Inductance with Magnetizing Current

Photograph of the experimental setup is shown in Fig.4. The oscillogram of stator voltage during a voltage build up process is shown in Fig.5. In this case prime mover speed is set at $1115 \mathrm{rpm}$. Stator voltage is taken through a 10:1 probe. Oscilloscope settings are $13.6 \mathrm{~V} / \mathrm{div}$ and $20 \mathrm{~ms} / \mathrm{div}$. At this speed of $1115 \mathrm{rpm}$, SEIG is loaded using a lamp load of $200 \mathrm{~W} /$ phase. The corresponding stator voltage waveform is shown in Fig.6, with same oscilloscope settings as in Fig.5. The stator voltage waveform during a build up process at 1440 rpm is shown in Fig.7. The stator current waveform when it is loaded with 200W/phase is shown in Fig.8. Stator voltage 
waveform during a build up process at $1750 \mathrm{rpm}$ is shown in Fig.9. Fig.10 shows that for low values of speed (in this case $1090 \mathrm{rpm}$ ), the voltage collapses and fails to build up.

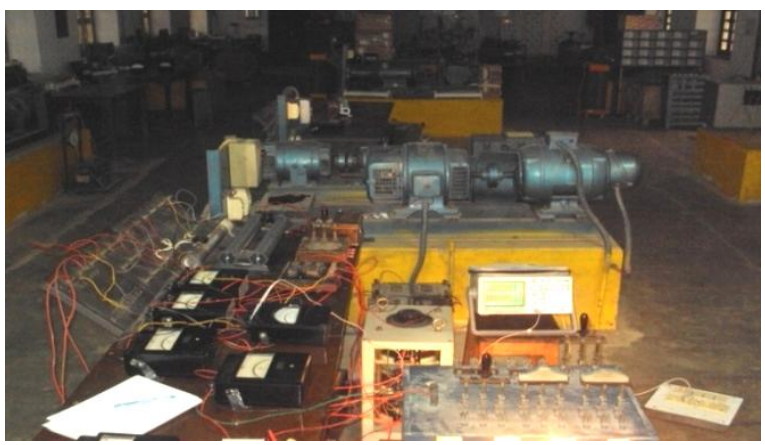

Fig.4. Experimental set-up

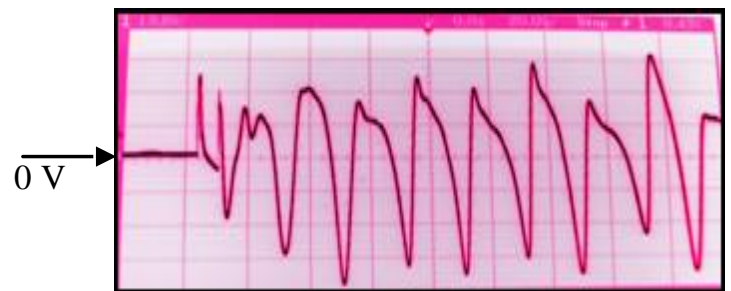

Fig.5. The voltage build up at a prime mover speed of $1115 \mathrm{rpm}$

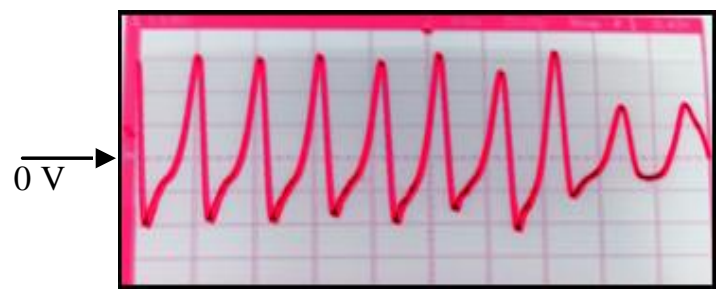

Fig.6. Stator voltage with a $200 \mathrm{~W} /$ phase lamp load at a prime mover speed of $1115 \mathrm{rpm}$

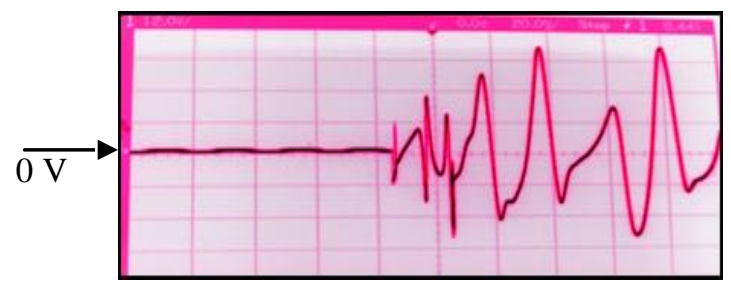

Fig.7. The voltage build up process for a prime mover speed of $1440 \mathrm{rpm}$

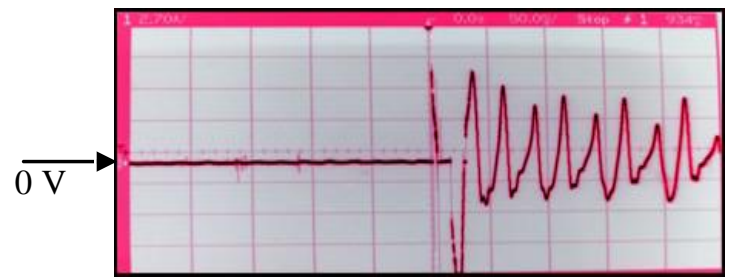

Fig.8. For a $200 \mathrm{~W} /$ phase lamp load the phase 'a' current with prime mover speed of $1440 \mathrm{rpm}$

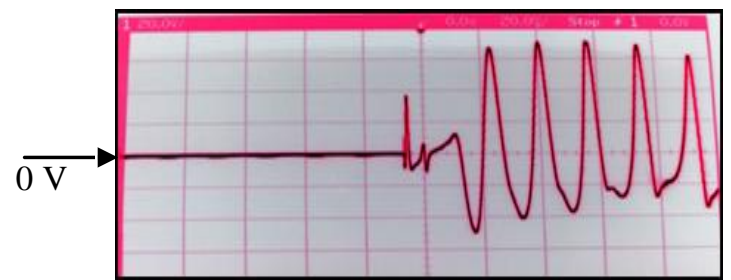

Fig.9. Voltage build up at a prime mover speed of $1750 \mathrm{rpm}$

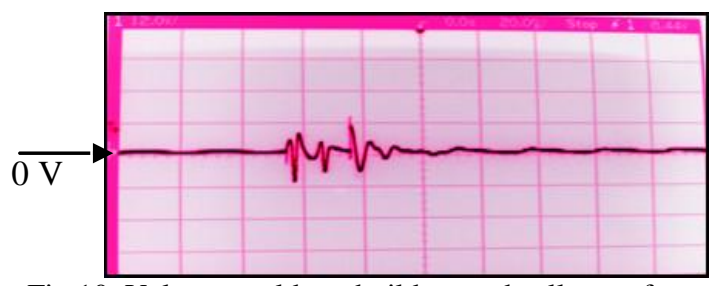

Fig.10. Voltage could not build up and collapses for a prime mover speed of $1090 \mathrm{rpm}$

The rating of capacitor bank is $2.6 \mathrm{kVAr}, 415 \mathrm{~V}, 5.1 \mathrm{~A}$. Each of three capacitance value comes out to be $48 \mu \mathrm{F}$.

\section{Voltage Control of SEIG}

A voltage control scheme for SEIG is shown in fig.11. The induction machine for dc link voltage control is modeled in stationary reference frame. Induction machine, pulse width modulated voltage source inverter, dc link capacitor and load, each component of the scheme is modeled separately. A $24 \mathrm{~V}$ battery is used for a period of 2 seconds for supplying the necessary magnetizing current through a pulse width modulated voltage source inverter to establish flux in the air gap required for self excitation. A DC link capacitor of $500 \mu \mathrm{F}$ in parallel with the diode maintains the voltage at set value. The voltage across the dc link capacitor is sensed and compared with the reference output voltage and passed through a discreet PI controller. The output of PI controller is converted to three phase reference waveforms and compared with a $5 \mathrm{kHz}$ triangular carrier to generate the sinusoidal modulated gate pulses. The voltage source inverter acts as a reactive power compensator. The switching instants are tracked by the PI controller from SEIG. The power flow to dc link capacitor is through a three phase diode bridge converter and the input power to SEIG is through a three leg IGBT converter.

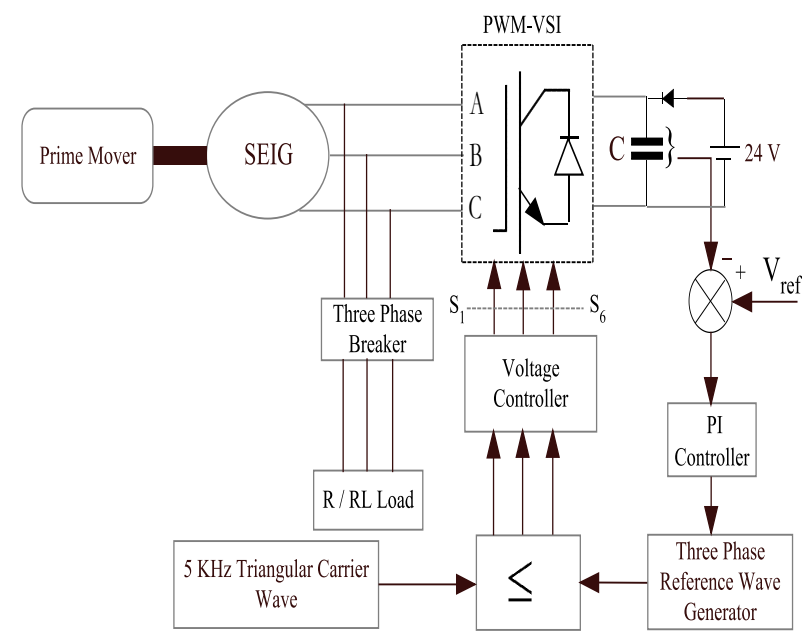

Fig.11. A voltage control scheme for Self-Excited Induction Generator

The voltage source inverter is modeled as :

$$
v_{a 0}=\frac{v_{d c}}{2} S F_{1 a}=\frac{v_{d c}}{2} \sum_{n=1}^{\infty} A_{n} \sin (n \omega t)
$$




$$
\begin{gathered}
v_{b o}=\frac{v_{d c}}{2} S F_{1 b}=\frac{v_{d c}}{2} \sum_{n=1}^{\infty} A_{n} \sin \left(n \omega t-120^{\circ}\right) \\
v_{c o}=\frac{v_{d c}}{2} S F_{1 c}=\frac{v_{d c}}{2} \sum_{n=1}^{\infty} A_{n} \sin \left(n \omega t+120^{\circ}\right)
\end{gathered}
$$

The dc link capacitor is modeled as :

$$
\begin{gathered}
\frac{d}{d t} v_{d c}=-\frac{i_{d c}}{C} \\
i_{d c}=S_{a} i_{e a}+S_{b} i_{e b}+S_{c} i_{e c}
\end{gathered}
$$

The set point of $V_{d c}$ must be greater than the peak value of the machine line voltage in order to force the desired line currents.

The voltage error at the kth sample is given by

$$
V_{\text {err }}(k)=V_{\text {ref }}(k)-V_{\text {mcal }(k)}
$$

The output of the PI controller, at the kth sample is expressed as

$$
\begin{gathered}
\omega(k)=\omega(k-1)+K_{I} T_{\text {samp }} V_{e r r}(k)+ \\
K_{P}\left(V_{e r r}(k)-V_{e r r}(k-1)\right)
\end{gathered}
$$

Where ' $\mathrm{K}_{\mathrm{P}}$ ' and ' $\mathrm{K}_{\mathrm{I}}$ ' are the proportional and integral controller gain constants. The gain constants are given in Appendix A.

\section{Simulation Results and Discussion}

MATLAB code is used to predict the generated voltage from a 10 h.p. three phase squirrel cage induction machine with an initial residual voltage of 10 volts rotating at a given speed with appropriate capacitors connected at the stator terminals to provide the necessary magnetizing current to establish the required flux in the air gap. The simulation results show that self excitation can be established and speeds on self-excitation investigated. Fig.12. shows the voltage build up in phase ' $a$ ' of induction machine with per phase excitation capacitance of $48 \mu \mathrm{F}$ at a rotor speed of $1200 \mathrm{rpm}$. It took about 2.2 seconds to settle to its steady state voltage of 300 volts. Fig.13, Fig.14 and Fig.15 show the generated voltage, line current, load current, active power, reactive power and electromagnetic torque responses. The load is $50 \Omega$ and $5 \mathrm{mH}$. Fig. 13 is for a speed of $1400 \mathrm{rpm}$ with excitation capacitance of $48 \mu \mathrm{F}$. Fig.14 is for a speed of $1800 \mathrm{rpm}$ with $48 \mu \mathrm{F}$ excitation capacitance. Fig. 15 is for an excitation capacitance of $100 \mu \mathrm{F}$, at $1800 \mathrm{rpm}$ speed. It can be observed from all these figures that as the speed increased from $1400 \mathrm{rpm}$ in Fig. 13 to $1800 \mathrm{rpm}$ in Fig. 14 keeping the load same at $50 \Omega$ and $5 \mathrm{mH}$, the reactive power variation too increased to the range of $-800 \mathrm{VAr}$ to $-1200 \mathrm{VAr}$ from the range of 170VAr to -200VAr. In Fig.15 as the per phase capacitance value increased to $100 \mu \mathrm{F}$ for a speed of 1800 rpm there is a considerable increase in the reactive power from $-1000 \mathrm{VAr}$ to $-1300 \mathrm{VAr}$. The increase in active power variation and electromagnetic torque is also observed as a result of increase in speed and per phase excitation capacitance. Results are shown for a period of 0.2 seconds from 5 seconds to 5.2 seconds. Load is given at 4.5 seconds. As the speed increases the voltage build up starts early as a result of mutual inductance variation. It reaches to its saturation value early increasing the steady state voltage. As the mutual inductance depends on magnetizing current which in turn depends on direct axis and quadrature axis current, which is continuously increasing till the voltage reaches steady state, drawing more reactive power. Line current too is increased. The frequency of exchange of power is too increased so the frequency of line voltage and line current as the speed is increased as it can be observed from Fig. 13 and Fig. 14.

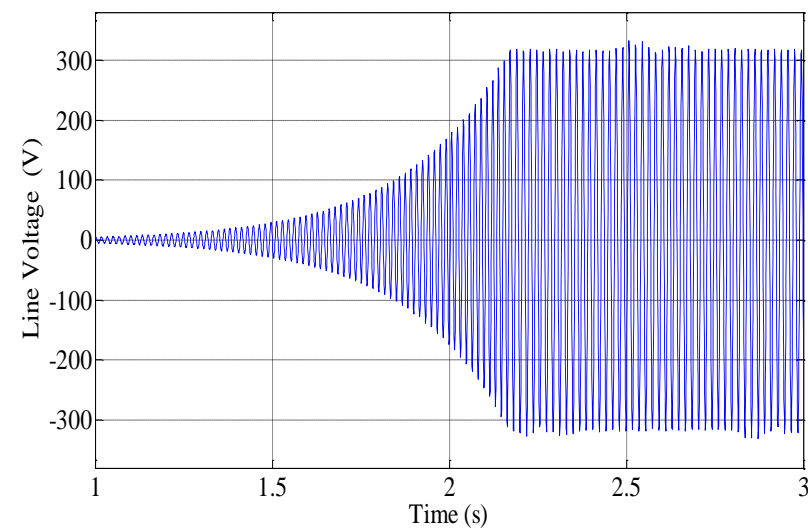

Fig. 12 The terminal voltage build up for $48 \mu \mathrm{F}$ at $1200 \mathrm{rpm}$
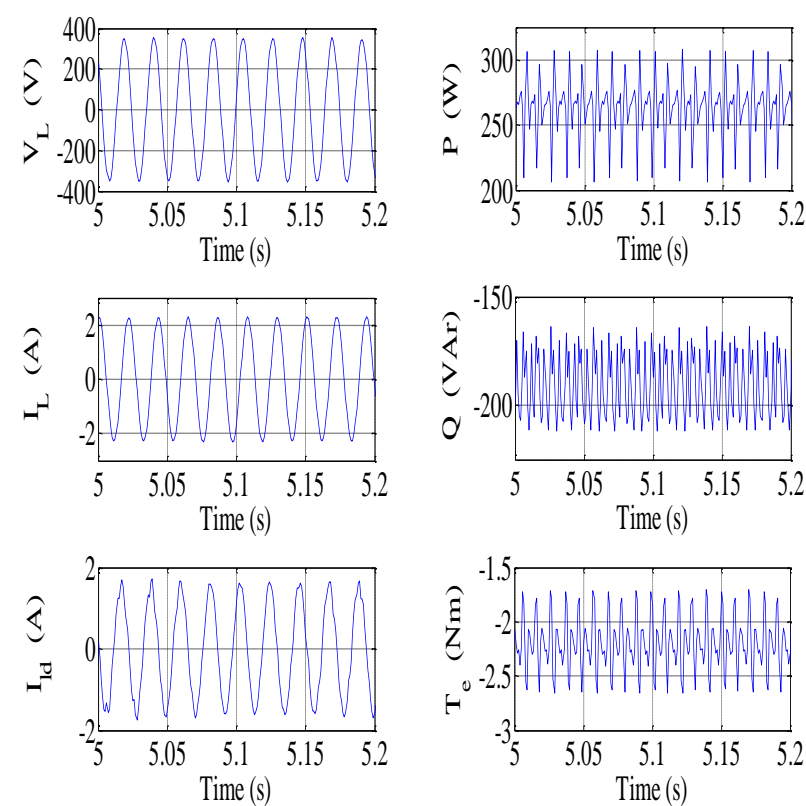

Fig. 13 The generated voltage, line current, load current, active power, reactive power and electromagnetic torque for a rotor speed of $1400 \mathrm{rpm}$ for a load of $50 \Omega$ and $5 \mathrm{mH}$ with $\mathrm{C}=48 \mu \mathrm{F}$

As the per phase excitation capacitance is switched to $100 \mu \mathrm{F}$ from $48 \mu \mathrm{F}$ the distortion in line current is apparent apart from the decrease in frequency as observed from Fig.14 and Fig.15. It happens because of a comparative delay in saturation of magnetizing inductance. Fig.16. shows the dc link capacitor voltage profile as it tracks the reference value of 400 volts at 
about 10 seconds. Fig.17 shows the generated voltage, line current, load current, active power and reactive power and electromagnetic torque variation when the machine runs at $1400 \mathrm{rpm}$ and is excited by a dc link capacitor through a pulse width modulated voltage source inverter with an error proportional gain of unity. Results are shown between 17 seconds to 18 seconds for a load of $600 \mathrm{~W}$ and $500 \mathrm{VAr}$. Reactive power varies between $50 \mathrm{VAr}$ to -70VAr. The line current is a distorted sinusoidal. Same results are shown in Fig.18 with error proportional gain of 0.8 . The line current gets a nearly sinusoidal shape with an increased frequency of about $150 \mathrm{~Hz}$. The voltage remains constant at 400 volts. Reactive power also increases.
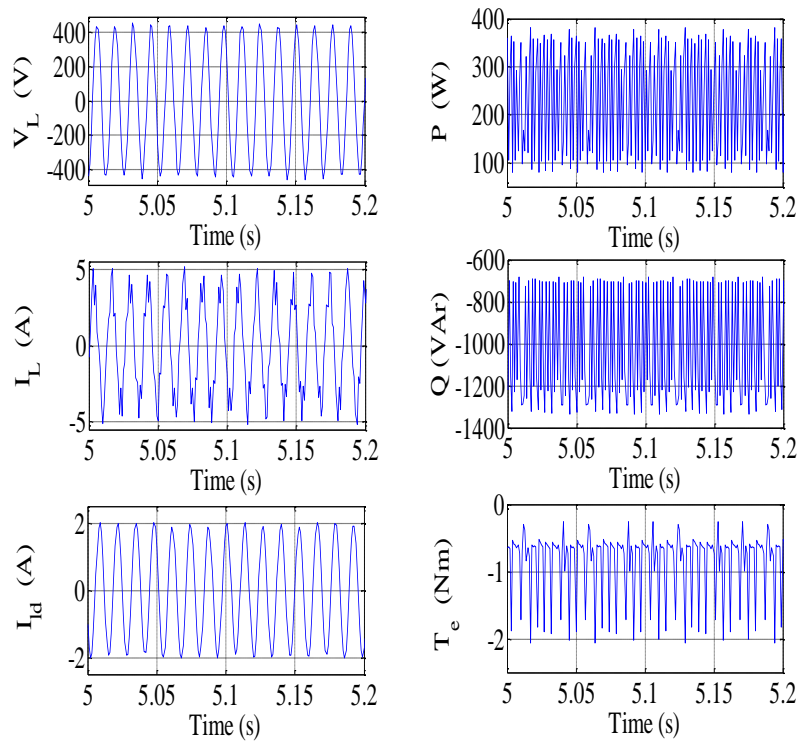

Fig.14 The generated voltage, line current, load current, active power, reactive power and electromagnetic torque for a rotor speed of $1800 \mathrm{rpm}$ for a load of $50 \Omega$ and $5 \mathrm{mH}$ with $\mathrm{C}=48 \mu \mathrm{F}$
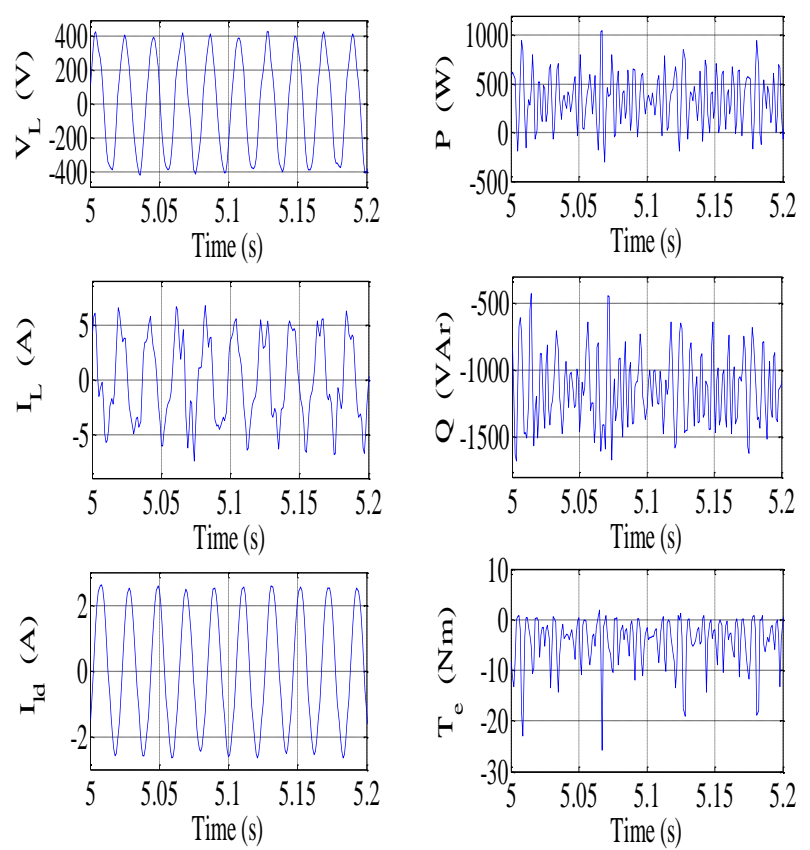

Fig. 15 The generated voltage, line current, load current, active power, reactive power and electromagnetic torque for a rotor speed of $1800 \mathrm{rpm}$ for a load of $50 \Omega$ and $5 \mathrm{mH}$ with $\mathrm{C}=100 \mu \mathrm{F}$

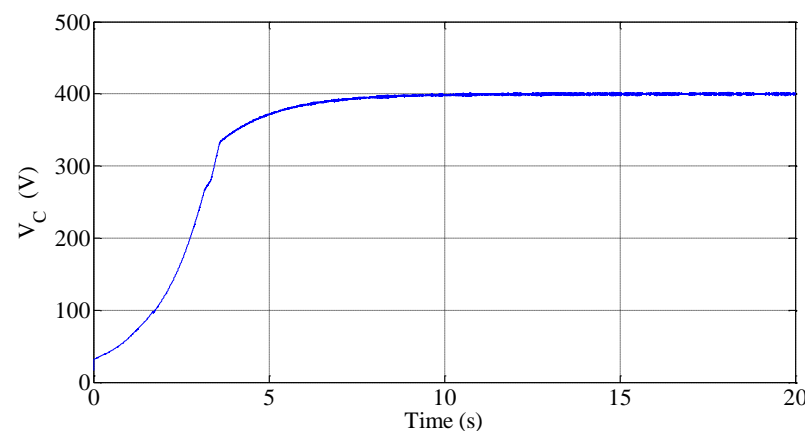

Fig.16 DC link capacitor voltage profile for $48 \mu \mathrm{F}$ at $1800 \mathrm{rpm}$

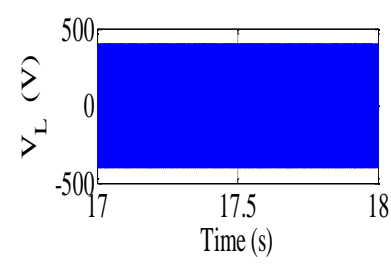

(a)

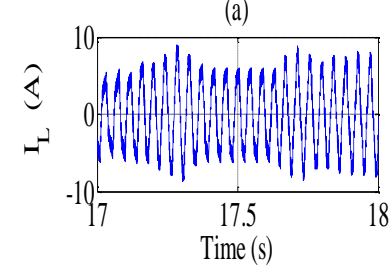

(b)

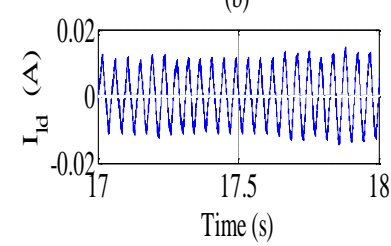

(c)

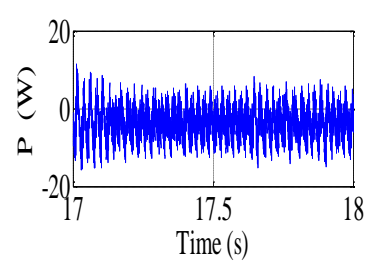

(d)

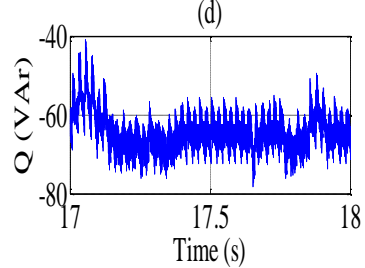

(e)

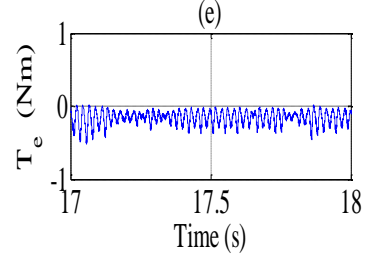

(f)
Fig. 17 The generated voltage, line current, load current, active power, reactive power and electromagnetic torque for a rotor speed of $1400 \mathrm{rpm}$ for a load of $600 \mathrm{~W}$ and 500VAr with dc link capacitor of $500 \mu \mathrm{F}$ with unity gain
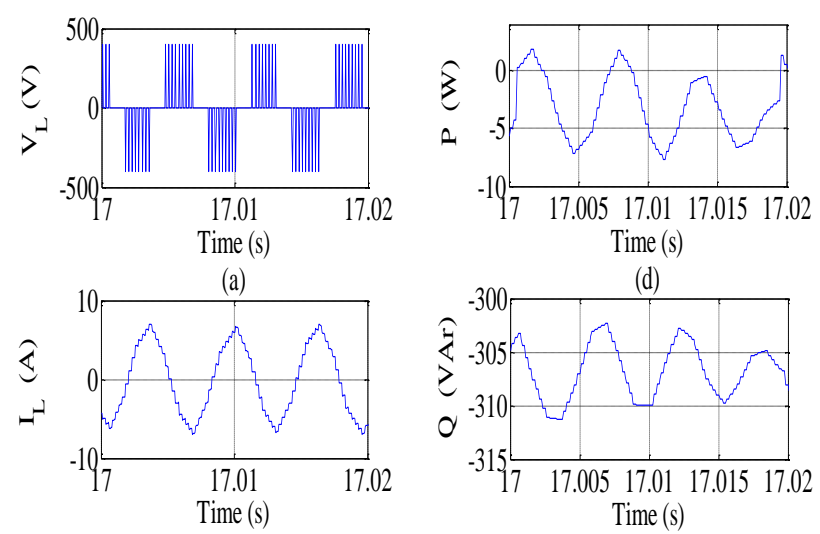

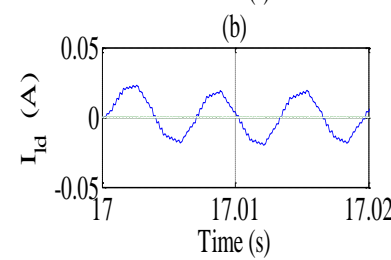

(c)

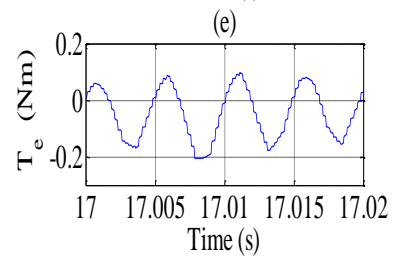

(f)
Fig. 18 The generated voltage, line current, load current, active power, reactive power and electromagnetic torque for a rotor speed of $1400 \mathrm{rpm}$ for a load of $600 \mathrm{~W}$ and 500VAr with dc link capacitor of $500 \mu \mathrm{F}$ with 0.8 gain 


\section{Conclusion}

This paper discusses the operation of an induction machine under standalone generating mode and a generating scheme for constant voltage and variable frequency by a proportional gain control technique. A laboratory test is performed where the induction machine is controlled as a self excited induction generator. The dynamic analysis of a self excited induction generator is done and the effect of rotor speed and excitation capacitance is observed. From the simulation and experimentation, it is confirmed that as the capacitance is increased at a particular speed, voltage builds up faster and the magnitude of voltage increases due to availability of more VAR. But frequency remains constant. As the speed increases at a fixed capacitance, both magnitude and frequency of generated voltage increases. The capacitive current is limited to a value less than the current rating of the induction generator. The effect of increased speed and higher capacitance on dynamic reactive power variation, voltage and frequency of output voltage is also observed. The output voltage is controlled to give a constant voltage by a simple scalar dc link voltage control scheme. The frequency of the current can be controlled by varying the error gain of the discrete PI controller. The PWM VSC between generator and dc link is also controlled as a static VAr compensator to provide VAR to the induction generator.

\section{Appendix A}

Induction Machine parameters

Rating of the induction machine $10 \mathrm{hp}, 415 \mathrm{~V}, 14.6 \mathrm{~A}, 4$ pole, and its parameters are as follows:

$$
R_{s}=0.6837 \Omega ; R_{r}=0.451 \Omega ; X_{l s}=X_{l r}=1.304 \Omega \text {. }
$$

PI Controller Gain Constant

$$
K_{P}=23 ; \quad K_{I}=14 \text {. }
$$

\section{References}

[1] Singh, G.K., "Self-excited induction generator research-a survey", Electric Power Systems Research, 69, 2004, pp.107-114.

[2] Salama, M.H. and Holmes, P.G., "Transient and steadystate load performance of stand-alone self-excited induction generator", IEE Proc. - Electr. Power Appl., vol. 143, no.1, January 1996, pp.50-58.

[3] Malik, N.H. and Haque, S.E., "Steady-state analysis and performance of an isolated self-excited induction generator", IEEE Trans. on Energy Conversion, vol. EC1, no.3, 1986, pp.134-139.

[4] Malik, N.H. and Mazi, A.A, "Capacitance requirements of self-excited induction generators", IEEE Trans. on Energy Conversion, vol. EC-2, no.1, 1987, pp.2-9.

[5] Debta, Birendra Kumar and Mohanty, K.B., "Analysis on the effect of dynamic mutual inductance in voltage build up of a stand-alone brushless asynchronous generator", Procc. of National Power Electronics Conference, IIT Roorkee, June 2010.
[6] Mustafa A. Al-Saffar, Eui-Cheol Nho, Thomas A. Lipo, "Controlled shunt capacitor self-excited induction generator", IEEE Conference on Industrial App., vol. 2, pp.1486-1490, October 1998.

[7] Jayaramaiah, G.V. and Fernandes, B.G., "Novel Voltage Controller for Stand-alone Induction Generator using PWM-VSI", IEEE Conference on Industry Applications, vol. 1, October 2006, pp.204-208.

[8] Venkatesa Perumal, B. and Chatterjee, Jayanta K., "Voltage and Frequency Control of a Stand Alone Brushless Wind Electric Generation Using Generalized Impedance Controller", IEEE Trans. on Energy Conversion, vol. 23, no.2, June 2008, pp.632-641.

[9] Ali Nesba, Rachid Ibtiouen, Toohami, "Dynamic performance of self-excited induction generator feeding different static loads", Serbian Journal of Electrical Engineering, vol. 3, no.1, June 2006, pp.63-76.

[10] Vadhere Shelly and Sandhu, K.S., "Constant voltage operation of self excited induction generator using optimization tools", International Journal of Energy and Environment, issue 4, vol. 2, 2008.

[11] Simoes, M. Godoy, Farret, Felix A., "Alternative Energy Systems: Design and Analysis with Induction Generators", Second Edition, CRC Press, Boca Raton, 2007, Chapter 5, pp.93-99. 